\title{
القدرة التنبؤية لمقياس ناجليري الأمريكي بمقياس موهبة المطبق في المملكة العربية السعودياة
}

\author{
شاهر خالد سليمان \\ أستاذ دكتور في قسم التربية وعلم النفس- كلية التربية والآداب- جامعة تبوك- المملكة العربية السعودية \\ مي عبدالله الجاسر \\ قسم التربية وعلم النفس- كلية التربية والآداب- جامعة تبوك- المملكة العربية السعودية \\ mayaljasir.k.s.a@gmail.com
}

هدف البحث لتطبيق مقياس ناجليري الأمريكي للكشف عن الموهوبين في البيئة السعودية والتحقق من وجود علاقة ارتباطية ذات دلالة

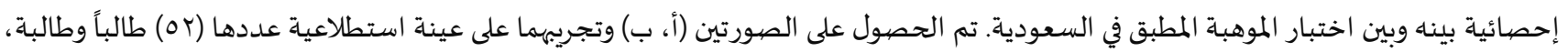

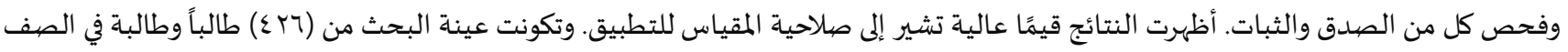

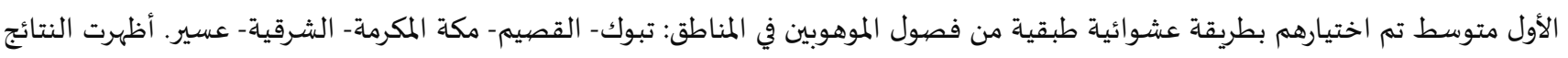
وجود فرق دال إحصائيا بين المتوسط الحسابي لإجابات الطلاب والطالبات على المقياس لصالح الطالبات، ووجود علاقة ارتباطية بين مقياس ناجليري

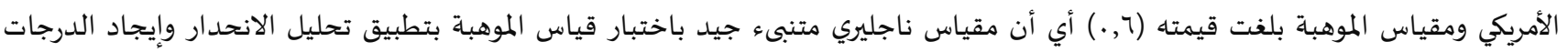

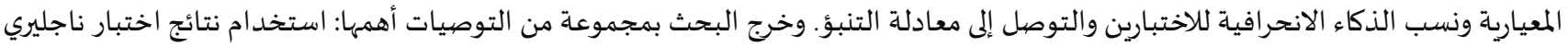

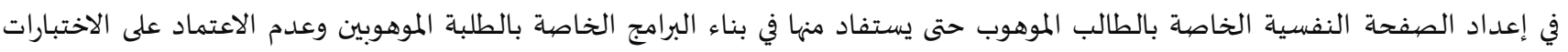
الجماعية في تصنيفهم واستخدام الاختبارات الفردية.

الكلمات المفتاحية: الاختبارات العالمية؛ العلاقة الارتباطية؛ الموهوبون.

\section{(c) (7)}

تعتبر عملية الكشف عن الموهوبين عملية غاية في الأهمية، لما يترتب على نتائجها من اتخاذ قرارات تكون لها آثارها السلبية إذا ما تم تصنيف

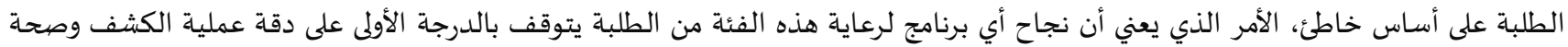

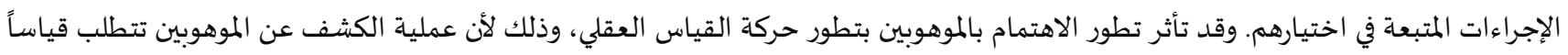

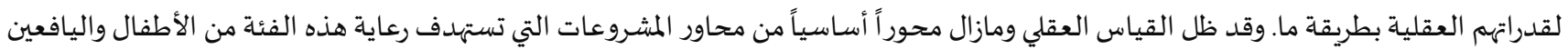

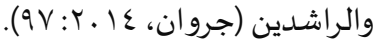

وتتم عملية اختيار الطلبة الموهوبين من خلال عدة مراحل بدايةً مرحلة (استقبال طلبات الترشيح)، حيث بلغ عدد المسجلين بالمشروع الوطني

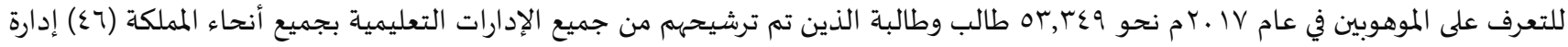
تعليمية للبنين، (7) إدارة تعليمية للبنات. ويسعى المشروع إلى توعية المجتمع بخصائص الموهوبين وأهمية رعايتهم ، والوقوف على أحدث الاختبارات والأساليب المحلية والعالمية لاكتشافهم وهذا ما يهدف إليه البحث حول مدى فاعلية اختبار قياس الموهبة ومدى علاقتـ الارتباطية بالمقاييس العالمية والتوصل إلى معادلة التنبؤ

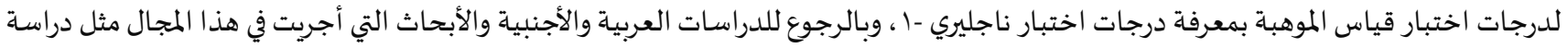

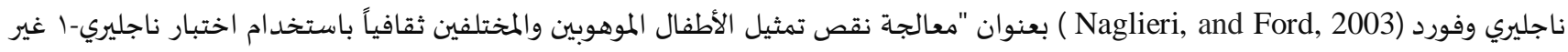

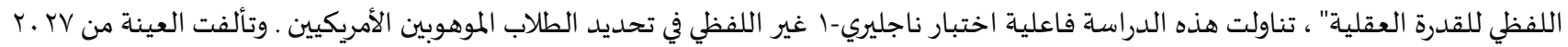


طالباً في الصفوف من رياض الأطفال وحتى الصف الثاني عشر كانوا من سكان الولايات المتحدة الأمريكية مع وجود عدد من المتغيرات الديموغرافية،

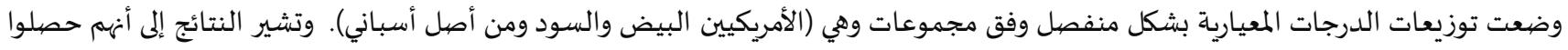

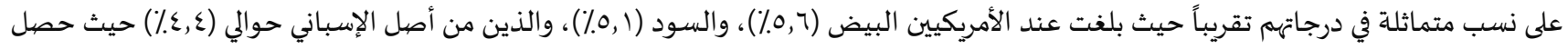

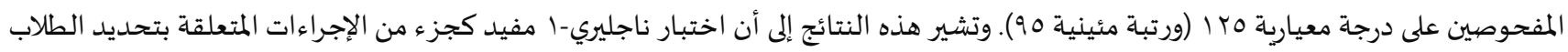

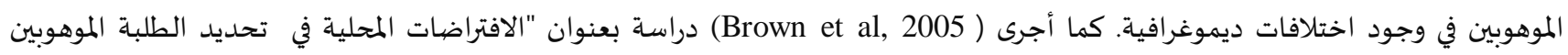

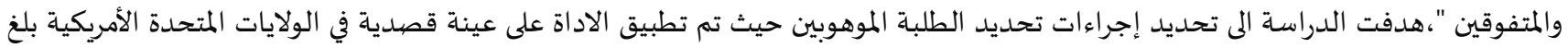

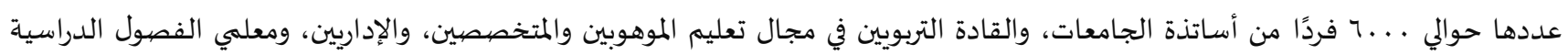

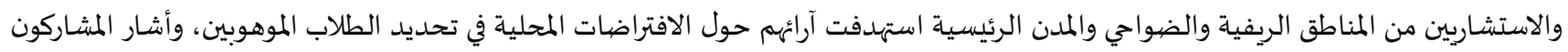

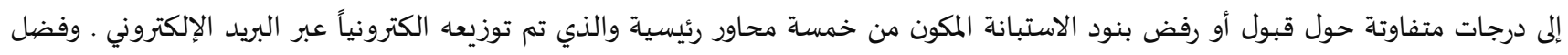

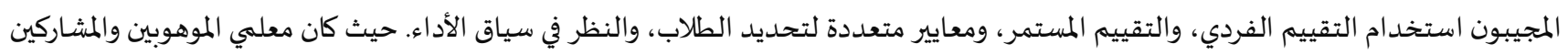

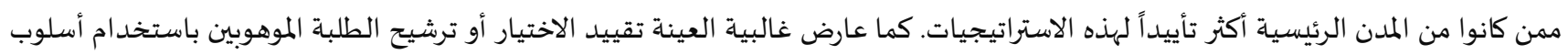

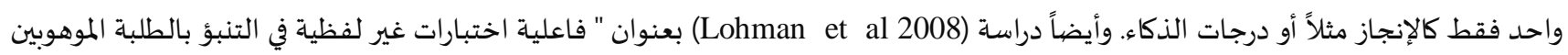

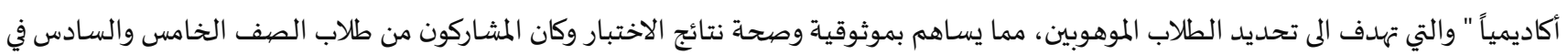

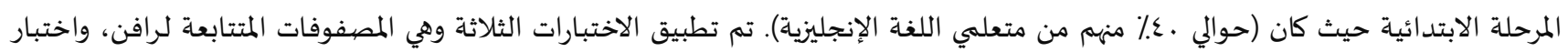

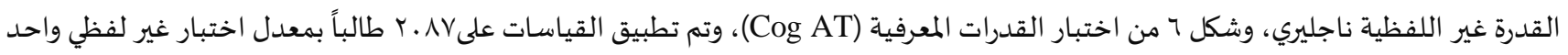

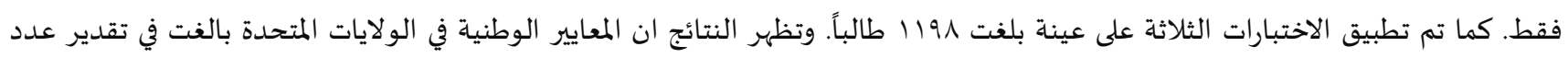

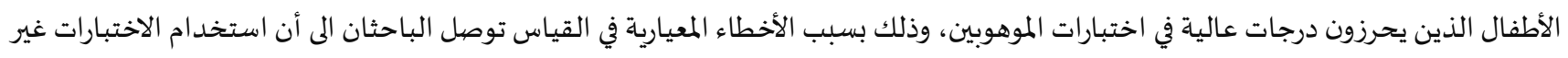

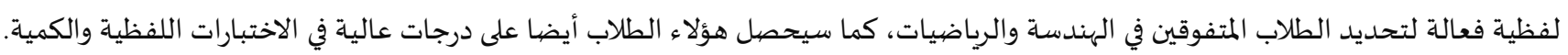
وكذلك أجرى كلاً من فيستا وكير (Vista and Care, 2011) دراسة بعنوان " فحص الفروق بين الجنسين لاختبار ناجليري-ا غير اللفظي" هدفت هذه الهذه الدراسـة لفحص الفروق بين الجنسين باستخدام اختبارات الذكاء غير اللفظية حيث تم تطبيق الصورة الصير أ من اختبار ناجليري -اغير اللفظي على عينة

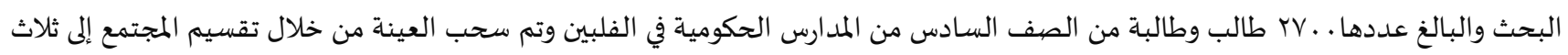

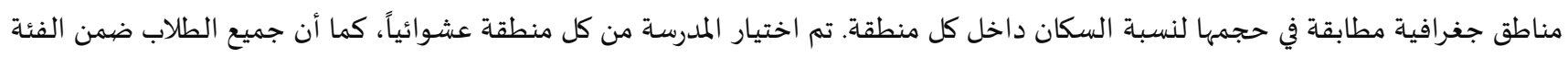

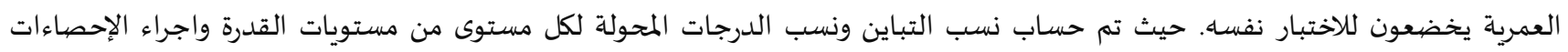

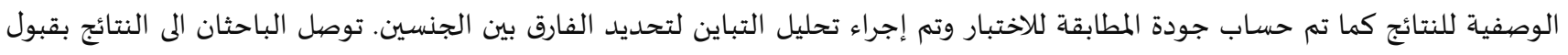
فرضية العدم أي أنه لا توجد فروق ذات دلالة احصائية بين الجنسين في متوسط درجاتهم. كما أجرى كلًا من (Gambrell and Alharbi, 2012)

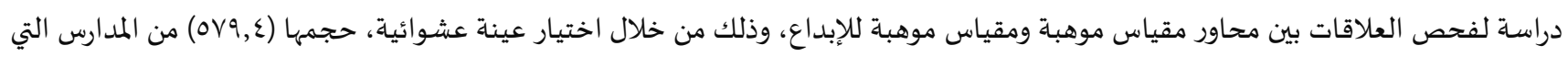

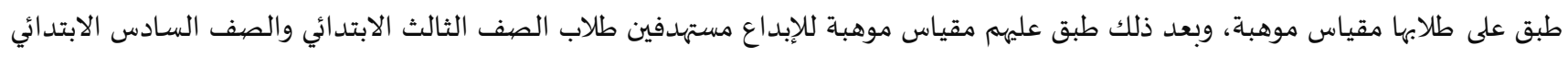
والصف الثالث المتوسط. وقد قارنت هذه الدراسة بين محاور المقياسين بتفصيل عميق. حيث ساعدات على دعلى التحقق من فرضياة النموذج "هل يستحق

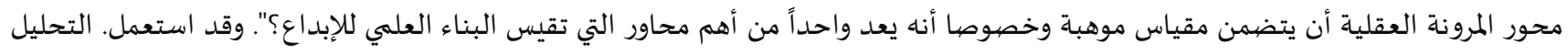

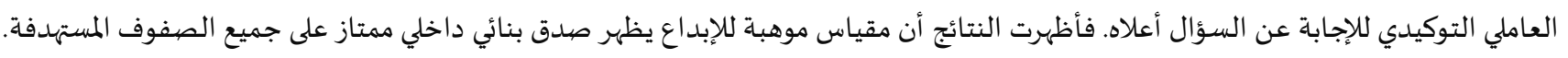

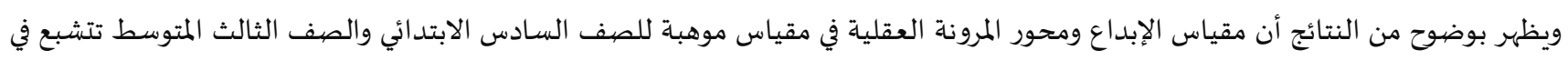

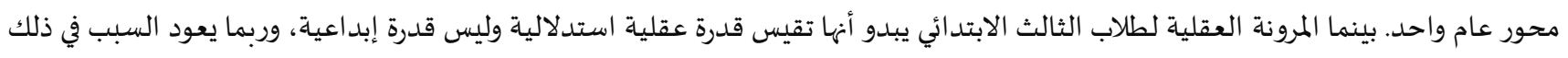

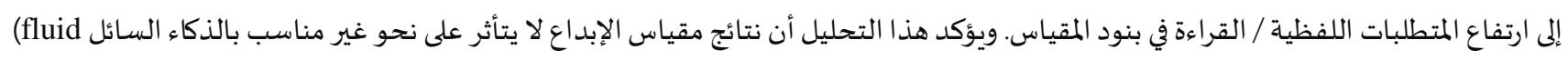

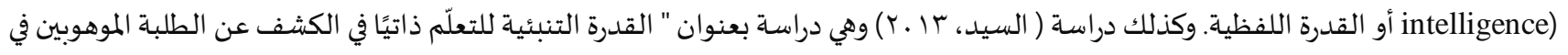

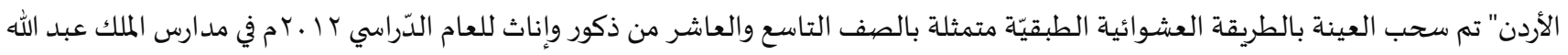

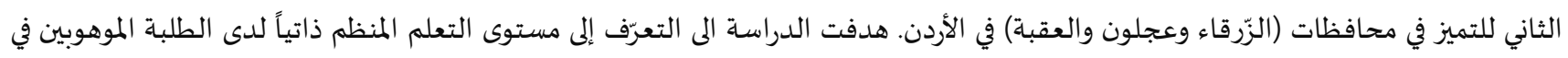

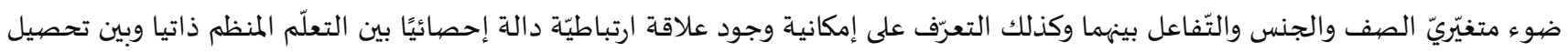

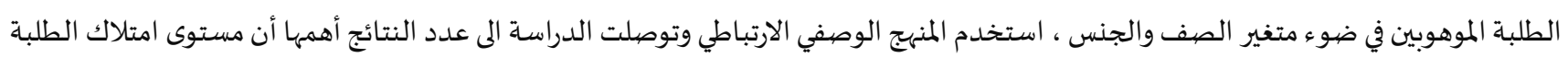

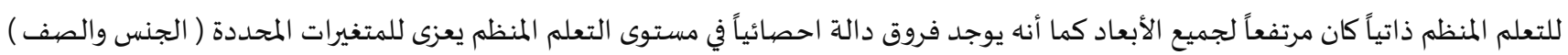

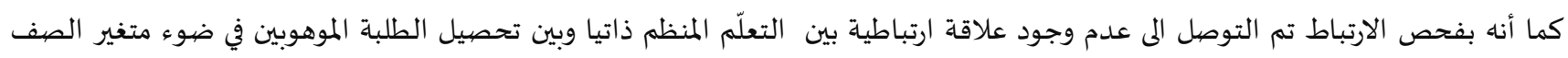
والجنس . وقام كلًا من ديمتريوف والحربي (Dimitrov and Alharbi , 2015) بدراسة هدفت إلى فحص البناء العاملي لمقياس موهبة، ومقياس موهبة 
للإبداع. والعلاقات المتبادلة بين محاور المقياسين. وأيضاً القدرة على التنبؤ بتصنيف أعلى 0؟ ٪من اخذي مقياس الإبداع. فكانت نتائج الدراسة أنه يوجد ارتباطات عالية بين محاور مقياس موهبة ومحاور مقياس الإبداع، مما أدى إلى وجود نموذج ملائم لنتائج المقياسين ذوي عاملين إلين من الدرجائ الثانية (second two factors order) مع بعض التمايز الناجم عن انخفاض الارتباط بين محاور المقياسين، مع ارتفاع الطلاب في المراحل الدراسية. واستخدم في هذه الدراسة أيضا النموذج اللوجستي الثنائي للتنبؤ بدرجات الطلاب في مقياس الإبداع من خلال متغيري الجنس ودرجات الطلاب في مقياس موهبة. كما إن تميز الدول المتقدمة يعود للعناية الفائقة بفئة الموهوبين وهذا بدوره ساعدها في الوصول إلى مراحل متقدمة في السلم الحضياري،

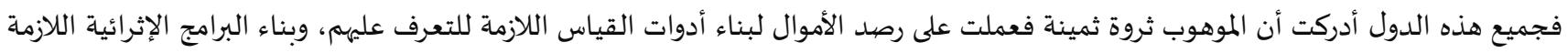

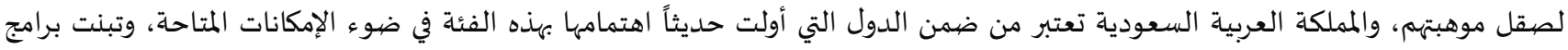
الكشف عن الموهوبين ورعايتهم وذلك من خلال المؤتمرات والندوات العلمية ومراكز الموهوبين، إلا إنه قد لوحظة فونسية في الآونة الأخيرة اهتمامًا واضحًا وواسعًا للموهوبين بإتباع اختبارات ومقاييس محلية باعتبارها معاييرًا خاصة لتحديد تلك الفئة مع إغفال الكشف عن عن هذه الموهبة باستخدام

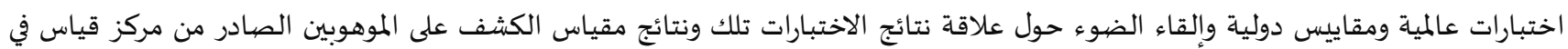

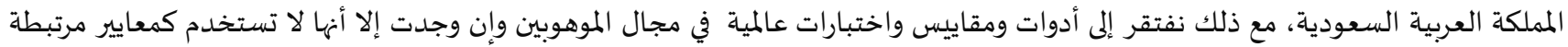

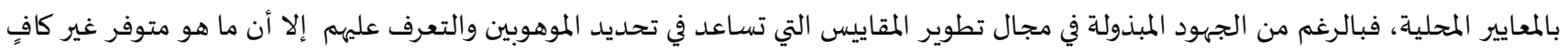

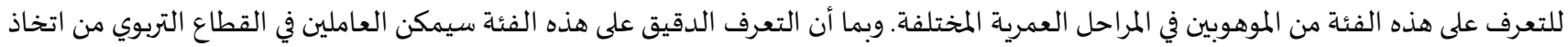

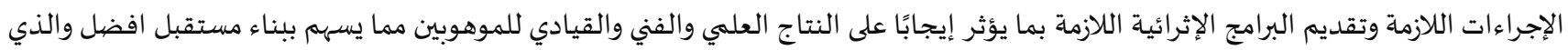

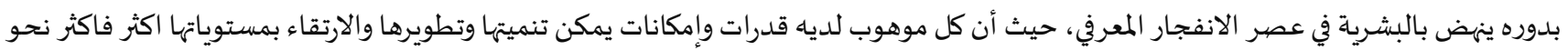

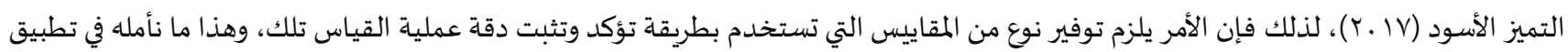

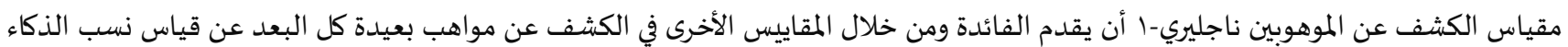
والقدرات العقلية.

أسئلة الدراسـة: يسعى البحث الحالي لإجابة على التساؤلات التالية:

ما الدرجات الموزونة (جداول المعايير) لاختبار موهبة واختبار ناجليري للموهبة على البيئة السعودية؟ هل يوجد فرق دال إحصائياً بين المتوسطات الحسابية لدرجات الطلاب والطالبات في الصف الأول متوسط في فصول الموهوبين على اختبار

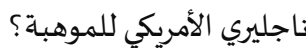
هل يوجد فرق دال احصائياً بين متوسط درجات الطلبة في الصف الأول متوسط في فصول الموهوبين على اختبار ناجليري للموهبة ومتوسط

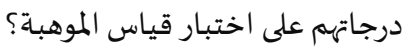
ما القدرة التنبؤية لاختبار ناجليري الأمريكي للموهبة بمقياس الموهبة المطبق في المملكة المباسية العربية السعودية؟

أهداف الدراسـة:

كما هدف البحث إلى تطبيق مقياس ناجليري الأمريكي للكشف عن الموهوبين في البيئة السعودية من خلال: إيجاد الدرجات الموزونة (جداول المعايير) لاختبار موهبة واختبار ناجليري للموهبة على البيئة السعودية. التحقق من وجود فرق دال إحصائياً بين المتوسط الحسابي لدرجات الطلاب والطالبات في اختبار ناجليري الأمريكي للموهبة. التحقق من وجود فرق دال احصائياً بين متوسط درجات الطلبة على اختبار ناجليري للموهبة ومتوسط درجاتهم على اختبار قياس الموهبة. التأكد من القدرة التنبؤية لاختبار ناجليري الأمريكي للموهبة بمقياس الموهبة المطبق في المملكة العربية السعودية. أهمية البحث: إن ما وصل إليه المجتمع الانساني من تنوع في التخصصات والأدوار التي يقوم بها الافراد دليل واضح على وجود فروق فردية بين الجماعات

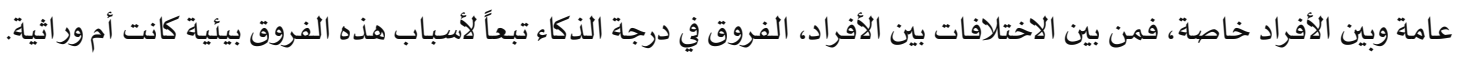


تعد الاختبارات بأنواعها المختلفة، والمتنوعة، من أهم الأدوات المستخدمة في علم النفس للتوصل الى فهم أعمق، ومعرفة أكثر شمولا لطبيعة

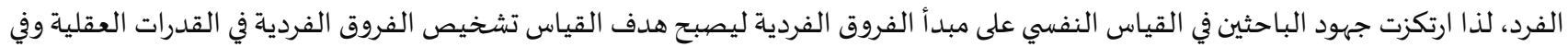

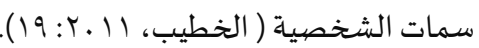

ويكتسب البحث الحالي أهميته من عدة منطلقات، الأهمية البحثية والتطبيقية من جانب، ومن منطلق الأغراض التي يحققها اختبار ناجليري

(NNAT-1)

في حدود علم الباحثين فإن هذا البحث يعد الأول في تطبيق اختبار ناجليري غير اللفظي في الدول العربية ومن ضمنها المملكة العربية السعودية.

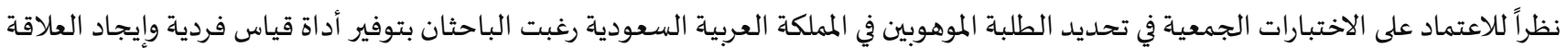

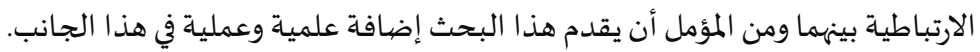
فيما يكتسب هذا البحث أهمية أخرى من ناحية الأغراض التي يحققها اختبار ناجليري غير اللفظي ومن أهمها ما يلي: التحقق من دقة عملية تصنيف الطلبة.

إعطاء الفرصة للفاحص بتدوين ملاحظاته بشكل دقيق والوصول الى تقييم أكثر دقة.

حلدود البحث:

يركز البحث على تطبيق مقياس الكشف عن الموهوبين ناجليري في البيئة السعودية، وذلك وفق ما يلي: الحدود البشرية: تحدد مجتمع البحث بطلاب وطالبات الصف الأول متوسط والملتحقين في فصول الموهوبين في المملكة العبية السعودياة. الحدود المكانية: تتمثل في فصول الموهوبين للصف الأول متوسط فيتهد في مدارس المملكة العربية السعودية.

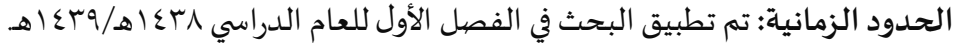

\section{مصبطلحات البحث:}

• الموهوب Gifted: عرّف (جراون، با • ب: وجr) الموهوب بأنه من يمتلك قدرة استثنائية أو استعداداً فطرياً غير عادي في مجال أو أكثر من المجالات العقلية والإبداعية والاجتماعية والانفعالية والفنية، وذلك بدلالة أدائه على اختبار أو أكثر من اختبارات الذكاء أو الاستعداد والإبداع ألماع والقيادة

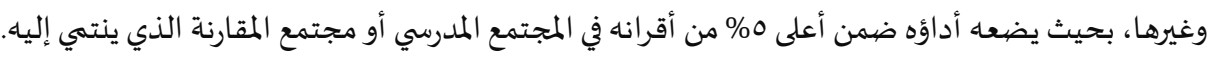

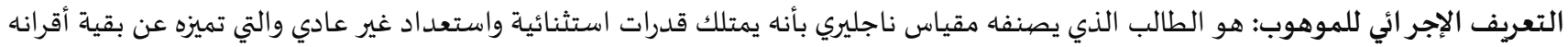
من حيث الدرجات المعيارية، وذلك بحصول الطالب على متوسط حسابي أعلى من أقرانه العاديين ليصنف من الموني الموهوبين.

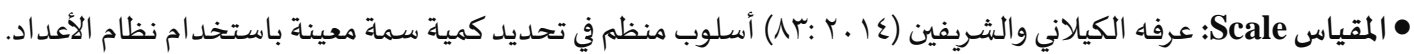
التعريف النظري: هو الأداة التي تتكون من مجموعة من الأسئلة او المثيرات التي تهدف لقياس عينة من السلوك وتقديرها بصورة كمية. (أبوزيد

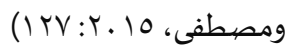
التعريف الإجر ائي: تم تعريفه بمجموعة من الأسئلة تم تحديد فقراتها وطريقة الإجابة عنها وتصحيحها بدقة، تقيس استجابات الطلبة نحو مقياس

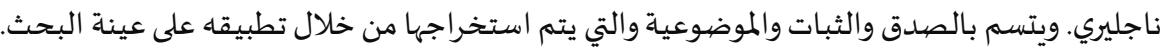
• مقياس الموهبة: هو مقياس للقدرات العقلية المتعددة يسهم في الكشف عن القدرات والمهارات الأكاديمية الكامنة لدى الطلبة في مجالات اللغة

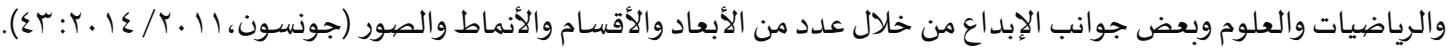

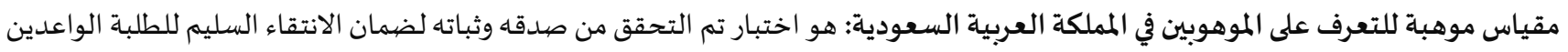

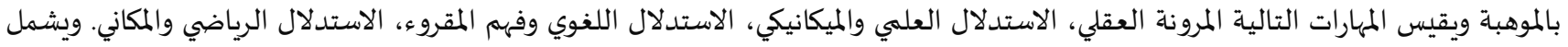

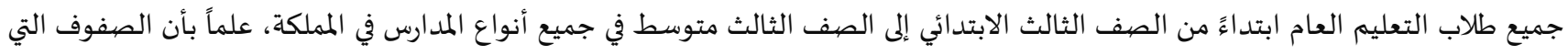
يطبَّق عليها اختبار موهبة هي: الصف الثالث الابتدائي، الصف السادس الابتدائي، الصف الصفاد الثالث المتوسط. • اختبار ناجليري NNAT: هو اختبار يهدف إلى قياس القدرة العامة وكذلك يعد أداة للتنبؤ بالنجاح الأكاديمي مثل الاختبارات التقليدية للقدرة

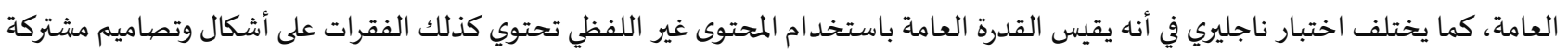
تربط بينها علاقات تتدرج في مستوى الصعوبة (Naglieri,2003:2 )، وتم بناء الاختبار ضمن آلية صنفت الأسئلة الم أربع قواعدي:

إكمال النمط Pattern Completion Reasoning by Analogy الاستدلال بالقياس لئسماس

التفكير التسلسلي Serial Reasoning. 
الإدراك البصري المكانيمpatial Visualization

الطريقة والاجراءات:

مجتمع البحث:

تكون مجتمع البحث من جميع الطلاب والطالبات الموهوبين في فصول الموهوبين في الصف الأول متوسط في التعليم العام حسب تصنيف ادارة

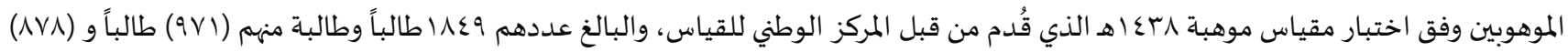

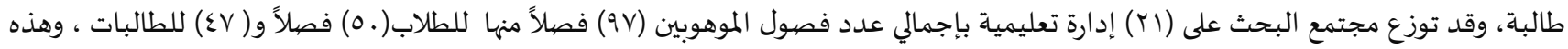

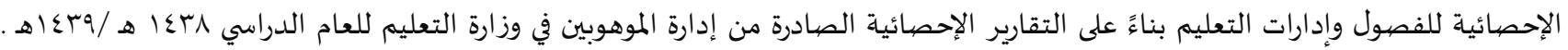

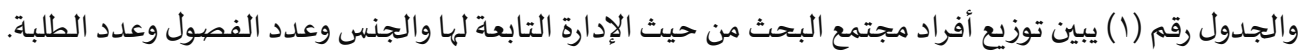

جدول( ) : توزيع أفراد مجتمع البحث من حيث الإدارة التابعة لها والجنس وعدد الفصهول وعدد الطبة

\begin{tabular}{|c|c|c|c|}
\hline ir. & 7 & بنين & \multirow[t]{2}{*}{ المدينة المنورة } \\
\hline 117 & 7 & بنات & \\
\hline$r 7$ & 1 & بنين & \multirow[t]{2}{*}{ المذنب } \\
\hline 10 & 1 & بنات & \\
\hline$\varepsilon$ & $r$ & بنين & \multirow[t]{2}{*}{ تبوك } \\
\hline$r \Lambda$ & $r$ & بنات & \\
\hline 11. & 0 & بنين & \multirow[t]{2}{*}{ جدة } \\
\hline 1.1 & 0 & بنات & \\
\hline$\varepsilon$ & $r$ & بنين & \multirow[t]{2}{*}{ حائل } \\
\hline$r \varepsilon$ & 1 & بنات & \\
\hline 10 & 1 & بنين & \multirow[t]{2}{*}{ سراة عبيدة } \\
\hline 1. & 1 & بنات & \\
\hline rv & $r$ & بنين & \multirow[t]{2}{*}{ عسير } \\
\hline ro & $r$ & بنات & \\
\hline$r$. & 1 & بنين & \multirow[t]{2}{*}{ عنيزة } \\
\hline$r$. & 1 & بنات & \\
\hline VV & $\varepsilon$ & بنين & \multirow[t]{2}{*}{ مكة المكرمة } \\
\hline$v \cdot$ & $\varepsilon$ & بنات & \\
\hline 00 & $r$ & بنين & \multirow[t]{2}{*}{ ينبع } \\
\hline$\varepsilon$ & $r$ & بنات & \\
\hline \multicolumn{2}{|c|}{$11 \leqslant 9$} & $9 V$ & المجموع الكلي \\
\hline $9 \times 1$ & 0. & بنين & \multirow[t]{2}{*}{ المجموع } \\
\hline$\Lambda V \Lambda$ & $\varepsilon V$ & بنات & \\
\hline
\end{tabular}

\begin{tabular}{|c|c|c|c|}
\hline عدد الطلاب & الفصول عدد & الجنس & إدارة التعليم \\
\hline $1 \ldots$ & 0 & بنين & \multirow[t]{2}{*}{ الأحساء } \\
\hline 91 & 0 & بنات & \\
\hline 10 & 1 & بنين & \multirow[t]{2}{*}{ البكيرية } \\
\hline $1 \pi$ & 1 & بنات & \\
\hline 10 & 1 & بنين & \multirow[t]{2}{*}{ الحدود الشمالية } \\
\hline 17 & 1 & بنات & \\
\hline r) & 1 & بنين & \multirow[t]{2}{*}{ الدوادمي } \\
\hline 19 & 1 & بنات & \\
\hline$r$. & 1 & بنين & \multirow[t]{2}{*}{ الرس } \\
\hline r. & 1 & بنات & \\
\hline$\varepsilon$. & r & بنين & \multirow{2}{*}{ الرياض } \\
\hline rV & $r$ & بنات & \\
\hline $1 \ldots$ & 0 & بنين & \multirow[t]{2}{*}{ الشرقية } \\
\hline $1 . r$ & 0 & بنات & \\
\hline IV & 1 & بنين & \multirow[t]{2}{*}{ الطائف } \\
\hline 10 & 1 & بنات & \\
\hline 77 & $\varepsilon$ & بنين & \multirow[t]{2}{*}{ القصيم } \\
\hline or & $r$ & بنات & \\
\hline IV & 1 & بنين & \multirow[t]{2}{*}{ القنفذة } \\
\hline IV & 1 & بنات & \\
\hline$r$. & 1 & بنين & \multirow[t]{2}{*}{ المخواة } \\
\hline 11 & 1 & بنات & \\
\hline
\end{tabular}

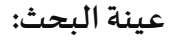

تكونت عينة البحث من (جrع) طالباً وطالبة في فصول الموهوبين في الصف الأول متوسط، والذين تم اختيارهم بالطريقة العنقودية حيث تم

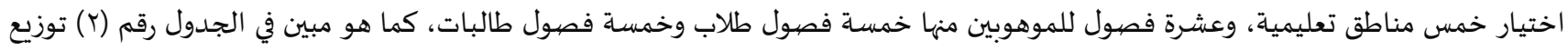
أفراد عينة البحث من حيث الجنس والإدارات التعليمية وعدد الطلبة. 
جدول(r) ) توزع أفراد عينة البحث من حيث الجنس والإدارات التعليمية وعدد الطلبة

\begin{tabular}{|c|c|c|c|c|}
\hline \multicolumn{2}{|c|}{ 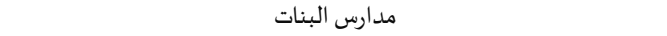 } & \multicolumn{2}{|c|}{ مدارس البنين } & \multirow[b]{2}{*}{ الإدارة التعليمية } \\
\hline نسبة عدد الطالبات من العينة الكلية & عدد الطالبات المتقدمين للاختبار & نسبة عدد الطلاب من العينة الكلية & عدد الطلاب المتقدمين للاختبار & \\
\hline$\% १, \varepsilon$ & $\varepsilon$. & $\% १, \varepsilon$ & $\varepsilon$. & المنطقة الشرقية \\
\hline$\% १, \varepsilon$ & $\varepsilon$. & $\% १, \varepsilon$ & $\varepsilon$. & 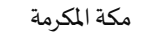 \\
\hline$\% १, \varepsilon$ & $\varepsilon$. & $\% १, \varepsilon$ & $\varepsilon$. & القصيم \\
\hline$\% \backslash \varepsilon, 0$ & Tr & $\% 1 \cdot, r$ & $\varepsilon \varepsilon$ & تبوك \\
\hline$\% १, \varepsilon$ & $\varepsilon$. & $\% १, \varepsilon$ & $\varepsilon$. & عسير \\
\hline$\% \circ r, 1$ & Trt & $\% \leqslant \vee, q$ & $r \cdot \varepsilon$ & المجموع \\
\hline$\% 1 \ldots$ & النسبة الكلية النسية & $\varepsilon r\}$ & ل ل لاب والطالبات & المجمو: - المو \\
\hline
\end{tabular}

أداة البـحث:

تم استخدام اختبار ناجليري -اغير اللفظي، وهو اختبار لقياس التفكير ومهارات حل المشكلات وتصنيف الطلاب الموهوبين، بحيث يعتبر اختباراً محايداً ثقافياً كما أن الاختبار يتضمن على الأشكال والتصاميم المجردة، والتي تسمح لاستجابات غير متحيزة بغض النظر عن لغة المفحوص الأسـاسية، والتعليم، والخلفياة الاجتماعية والاقتصادية .كما يستخدم في عرض الأسئلة لونين هما (الأصفر والأزرق) مما يساهم في التمييز الدقيق للبنود، ويستخدم كأداة للقبول في برامج الموهوبين في هيوستن، TX ، و فرجينيا بيتش، VA ، ونيويورك NY، وكذلك في العديد من المدن الأخرى. مواصفـات اختبارناجليري: اختبار فردي التطبيق. هـاج مب دقيقة فقط لتطبيقه.

$$
\text { • متوفر ورقي. }
$$

يوفر معاييرًا محددة في تصنيف الطلاب، مما يجعله اختباراً يساهم في تحديد الطلاب الموهوبين. هتميز باعتماده على الصور، مما يساعد في سرعاة توضيح التعليمات وتطبيق الاختبارات. ها يتطلب أي لغة منطوقة أو مكتوبة، مما يجعلها مفيدة لمتعلمي اللغة الإنجليزية. يستخدم اختبـار ناجليري لقياس ما يلي:

القدرة العقلية العامة General Ability. لقياس الطاب اللذين مهاراتهم في اللغة الإنجليزية محدودة أو حتى غير الناطقين باللغة الإنجليزية أومن خلفيات ثقافية متنوعة. الطلاب الموهوبين والمتفوقين. تقييم الطلاب ذوي المهارات المحدودة مثل ضعف السمع، والحد الأدنى من ضعف في الرؤية في مدارس التعليم العام. الطلاب من مستوى اقتصادي منخفض أو ظروف اجتماعية محدودة والذين يحصلون على المعرفة والمهارات اللفظية فقط. تم تجريب المقياس على عيناة استطلاعية مكونة من (ro) من الطلاب والطالبات من المجتمع وخارج العينة، تم حساب الصدق التلازمي للاختبار بإيجاد معامل الارتباط بين الدرجات على المقياس والدرجات على اختبار المصفوفات المتقدم لرافن حيث كانت قيمة معامل ارتباط بيرسون بين درجات الاختبارين (^, •) وهو دال عند مستوى ا . .,.. كما تم تطبيق المقارنة الطرفية بين مرتفعي ومنخفضي الأداء على الاختبار كان متوسط الفرق بين الموجوعتين دال إحصائيا عند مستوى ( . .,.) لصالح المجموعة العليا ، وللكشف عن معامل الثبات للمقياس باستخدام معامل كرونباخ ألفا وبلغت قيمتاء (عا, .) وتم حساباه بطريقة التجزئة النصفية وبلغت قيماة معامل الثبات باستخدام معادلة جتمان(VI, ..)كما بلغت قيمة معامل الثبات باستخدام معادلة سبيرمان لتصحيح معامل الارتباط (Y V, •) ، جميعها قيم عالية للصدق وللثبات تشير بصاحية المقياس للتطبيق. صدق وثبات مقياس ناجليري-ا للكشف عن الموهوبين: تعكس درجات الثبات اتساقًا قويًا بين العناصر داخل اختبار ناجليري-ا. وكلما زادت قيمة معامل الثبات كلما زادت الثقة في دقة عملية القياس . كما أن البنود تمتلك قيم ثبات ممتازة بمتوسط معامل الثبات مقداره ا و, .. حيث أنه تم فحص الصيدق من خلال التحقق صيدق البناءوذلك بعرض الاختبار على محكمين من ذوي الخبرة والاختصاص وتم استبعاد البنود غير الملائمة واعداد دليل تفصيلي لإجراءات صدق المحكمين بهدف تطوير الاختبار وتحسينه ، كما تم التحقق من الصدق من خلال الصدق المرتبط بمحك أو الصدق التلازمي وذلك بإيجاد العلاقة الارتباطية بينـه وبين اختبارات أخرى مثل اختبار مصفوفات رافن المتتابعة RSPM واختبار الذكاء غير اللفظي TONI-3 و اختبار وكسلر الطبعة الرابعة WISC-IV 


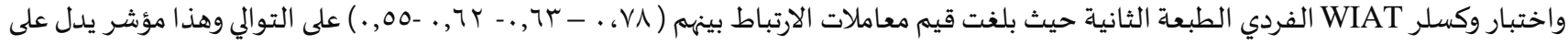
أن اختبار ناجليرى للقدرة غير اللفظي- 1 يقيس نفس السمة التي تقيسها الاختبارات السابقة والتي تهدف جميعها لقياس القدرة العقلية.

الصيدق المرتبط بمحك (التلازمي):

تم تطبيق اختبار ناجليرى-ا للقدرة غير اللفظي و مصفوفات رافن المتقدمة لـ(YOO) طالباً وطالبة من طلاب الصف الأول متوسط تتراوح

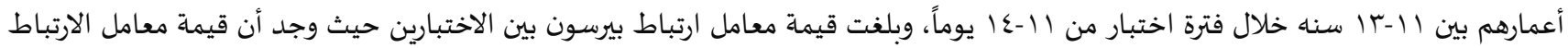

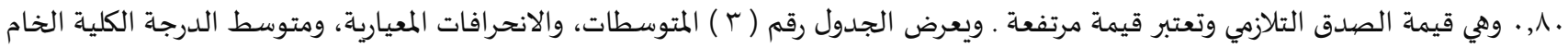

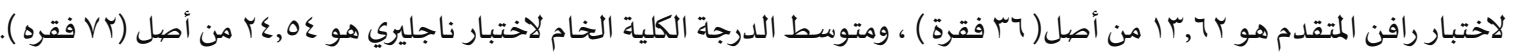
جدول(ץ): المتوسطات والانحرافات المعيارية ومعاملات الارتباط بين الاختبارين

\begin{tabular}{|c|c|c|c|c|}
\hline معامل الارتباط & الانحراف المعياري & المتوسط & عدد الأفراد & الاختبار \\
\hline$\cdot, \wedge$ & $r, \varepsilon r$ & $\mid r, \pi Y$ & or & اختبار رافن \\
\hline & 7,99 & $T \varepsilon, 0\}$ & or & اختبار ناجليري \\
\hline
\end{tabular}

الصيدق باستخدام الطريقة الطرفية في ترتيب الطلاب (الصيدق التميزي):

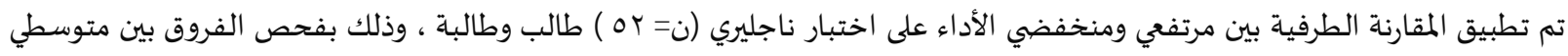

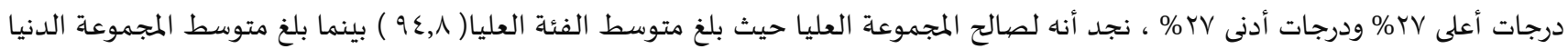

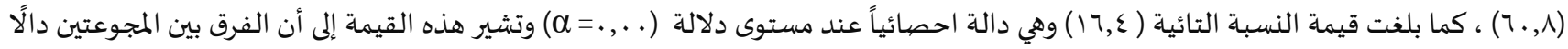

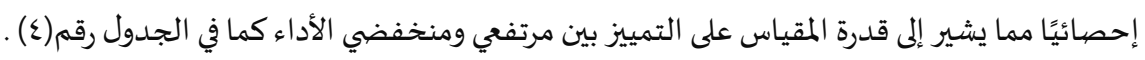

جدول(ع):المتوسطات والانحرافات المعيارية ومعاملات الارتباط بين الفئة العليا والفئة الدنيا

\begin{tabular}{|c|c|c|c|c|c|c|c|}
\hline مستوى الدلالة & قيمة T T & درجات الحرية & الانحراف المعياري & المتوسط & العدد & الفئات & البيان \\
\hline.,$\ldots$ & 17,0 & rT & 0,0 & $7 \cdot, \lambda$ & $1 \varepsilon$ & الفئة الدنيا & اختبار \\
\hline & & & 0,0 & $9 \varepsilon, \Lambda$ & $1 \varepsilon$ & الفئة العليا & ناجليري \\
\hline
\end{tabular}

التحقق من الثبات:

تم استخدام معامل كرونباخ ألفا، حيث بلغت قيمة معامل الثبات (V乏, V乏) .) وهذه قيمة تشير إلى صلاحية المقياس للتطبيق. كما استخدمت

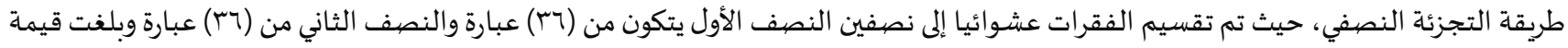

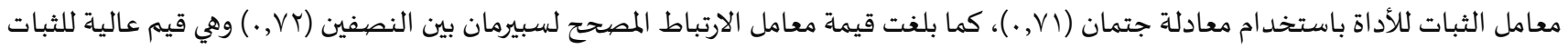
يمكن الوثوق بها كقيمة تؤكد صلاحية المقياس للتطبيق. تطبيق الاختبار على عينة البحث (جمع البيانات): بعد أن تم التحقق من صددق الاختبار بأكثر من طريقة والتحقق من الثبات كذلك وللوصيول الى نتائج أكثر دقة وموثوقياة، قامت الباحثة

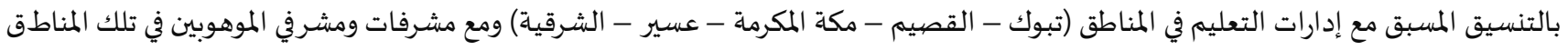
وبعد أخذ خطابات الموافقة على إجراء البحث وتطبيق الاختبار، تم تطبيق الاختبار على عينة عدد أفرادها حب عطالباً وطالبة في المناطق التي تم تحديدها لعينة البحث.

الأسـاليب الإحصائية:

في هذا البحث تم استخدام الأساليب الإحصيائية الآتيـة: ا. حساب الدرجات المعيارية لاختبار ناجليري واختبار موهبة. r. . معامل ارتباط (بيرسون) حيث تم حساب معامل الارتباط بين اختبار موهبة واختبار ناجليري (NNAT-1) .

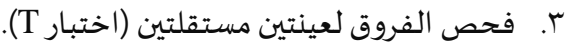
ع. علميل الانحدار. 
النتائج المتعلقة بالسؤال الأول: ما الدرجات الموزونة (جداول المعايير) لاختبار موهبة واختبار ناجليري للموهبة على البيئة السعودية؟"

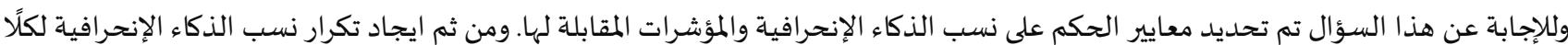

جدول(0): معايير الحكم على نسب الذكاء الإنحر افية

\begin{tabular}{|c|c|c|}
\hline نسبة الذكاء & الوصف & التصنيف \\
\hline . r rاوما فوقها & موهوب جدا & v \\
\hline Irq-1T. & موهوب & 7 \\
\hline $119-11$. & فوق المتوسط & 0 \\
\hline $1.9-9$ & متوسط & $\varepsilon$ \\
\hline ᄉ9-1. & متوسط منخفض & $r$ \\
\hline vq-v. & على الحدود & $r$ \\
\hline 7979 & قصور في الناحية الفكرية & 1 \\
\hline
\end{tabular}

جدول(7): تكرارنسب الذكاء الإنحر افية لاختبارناجليري

\begin{tabular}{|c|c|c|c|c|}
\hline المئين & المئين المصحح & تكرار متجمع صاعد & التكرارات & التصنيف \\
\hline 10,0 & 10,0 & 10,0 & 77 & $\varepsilon$ \\
\hline rr, & rT, & $r V, 7$ & $9 \varepsilon$ & 0 \\
\hline$r q, \varepsilon$ & $r q, \varepsilon$ & $v,$. & 171 & 7 \\
\hline$r r,$. & $r r,$. & $1 \ldots$, & $9 \wedge$ & v \\
\hline $1 \ldots$, & $1 \ldots$, & & 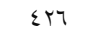 & المجموع \\
\hline
\end{tabular}

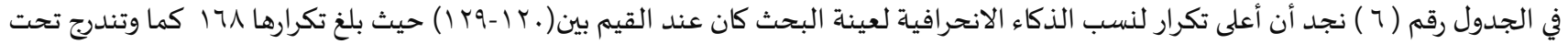

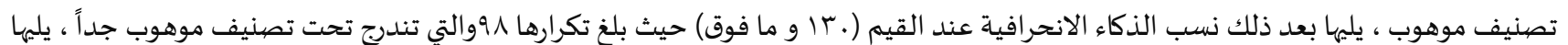
في الترتيب قيم نسب الذكاء الانحرافية عند (.11 (1 1) والتي تأتي ضمن تصنيف الأفراد فوق المتوسط وبلغ تكرار هذه الفئة ع9 ، بينما أقل تكرار كان

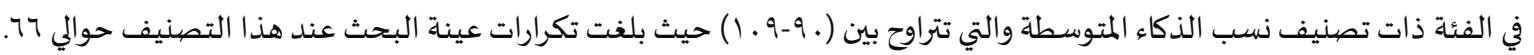

جدول(V) ( إ) تكرارنسب الذكاء الانحر افية لاختبارموهبة

\begin{tabular}{|c|c|c|c|c|}
\hline المئين & المئين المصحح & تكرار متجمع صاعد & التكرارات & التصنيف \\
\hline$r T, \varepsilon$ & $r r, q$ & $r r, q$ & ira & 7 \\
\hline $7 V, T$ & $T V, 1$ & $1 \ldots$, & YM & v \\
\hline $1 \ldots$, & $1 \ldots$, & & ETा & المجموع \\
\hline
\end{tabular}

في الجدول رقم (V) نجد أن اعلى تكرار لنسب الذكاء الانحرافية لعينة البحث كان عند القيم بين (.×l وما فوق) حيث بلغ تكرارها TM والتي تندرج

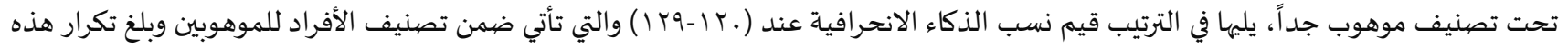
الفئة برا امن عينة البحث.

جدول (^): التوزيع التكراري للدرجات المعيارية ونسب الذكاء الانحر افية لاختبار" قياس الموهبة"

\begin{tabular}{|c|c|c|c|c|c|c|}
\hline المئين & المئين المصحح & تكرار متجمع صاعد & التكرارات & نسبة الذكاء الانحرافية & الدرجة المعيارية & الرقم \\
\hline., 9 & .,9 & ., & $\varepsilon$ & 119,90 & I,rr & .1 \\
\hline., 0 & .5 & $1, \varepsilon$ & $r$ & Irr,E. & 1,07 &.$r$ \\
\hline $1, \varepsilon$ & $1, \varepsilon$ & $r, \Lambda$ & 7 & $\mid r \varepsilon, \varepsilon 0$ & $1,7 \pi$ &.$r$ \\
\hline 1,9 & 1,9 & $\varepsilon, V$ & $\wedge$ & $1 r \varepsilon, q$. & 1,77 & $\varepsilon$ \\
\hline $0, r$ & $0, r$ & 9,9 & rY & $1 Y 0, .0$ & $1,7 V$ & .0 \\
\hline., 0 &., 0 & $1 ., r$ & $r$ & Iro,A. & I,VY & .7 \\
\hline$r, r$ & $r, r$ & $1 \%, 7$ & $1 \varepsilon$ & $1 Y 0,90$ & $1, V r$ &.$v$ \\
\hline., 9 & $\cdot, 9$ & $1 \xi, 7$ & $\varepsilon$ & $1 \pi 7, \varepsilon$. & 1,177 & .1 \\
\hline 0,7 & 0,7 & r., r & $r \varepsilon$ & $1 \pi V, \ldots$ & $1, \lambda$. & .9 \\
\hline., 0 &., 0 & $T \cdot, V$ & $r$ & ITV,VO & 1,10 & 1. \\
\hline., 0 &., 0 & $r 1,1$ & $r$ & $1 r V, q$. & 1,17 & 11 \\
\hline
\end{tabular}




\begin{tabular}{|c|c|c|c|c|c|c|}
\hline$r, \Lambda$ & $r, \Lambda$ & $r \varepsilon, q$ & 17 & $\mid T \Lambda, .0$ & $\mathrm{I}, \mathrm{AV}$ & ir \\
\hline., 9 &., 9 & ro, & $\varepsilon$ & IrA, ro & 1,19 & ir \\
\hline$\gamma, 0$ & $V, 0$ & Tr, & rr & $1 T \Lambda, 90$ & 1,94 & $1 \leqslant$ \\
\hline., 0 &., 0 & $r \mu, \Lambda$ & $r$ & $1 r q, 1$. & $1,9 \varepsilon$ & 10 \\
\hline 7,1 & 7,1 & $r q, 9$ & $r 7$ & $1 \Gamma ., .$. & $r, .$. & 17 \\
\hline., 0 &., 0 & $\varepsilon ., \varepsilon$ & $r$ & Ir., $\varepsilon_{0}$ & $r, \cdot r$ & iv \\
\hline., 9 &., 9 & $\varepsilon 1, r$ & $\varepsilon$ & $1 \pi 1, .0$ & $r, \cdot V$ & 11 \\
\hline., 0 &., 0 & $\varepsilon 1, \wedge$ & $r$ & $1 \pi 1,70$ & $r, 11$ & 19 \\
\hline 7,1 & 7,1 & $\varepsilon V, q$ & $r y$ & $1 \pi 1,90$ & $r, I r$ & $r$. \\
\hline., 0 &., 0 & $\varepsilon \wedge, \varepsilon$ & $r$ & Irr,v. & $r, 1 \Lambda$ & Fi \\
\hline 7,1 & 7,1 & $0 \leqslant, 0$ & $r 7$ & Irr,... & $r, r$ & rr \\
\hline., 9 &., 9 & $00, \varepsilon$ & $\varepsilon$ & $1 \pi r, 7$. & $r, r \varepsilon$ & $r$ \\
\hline., 0 &., 0 & 00,9 & $r$ & $1 \pi r, q$. & $r, r 7$ & $T \varepsilon$ \\
\hline$\varepsilon, Y$ & $\varepsilon, Y$ & $7 ., 1$ & 11 & $1 \Gamma \varepsilon, .0$ & $r, T V$ & ro \\
\hline., 0 &., 0 & $7 ., 7$ & $r$ & $T r \varepsilon, r$. & T,YA & r \\
\hline., 0 &., 0 & $71,$. & $r$ & $1 r \varepsilon, r_{0}$ & $r, r q$ & Tr \\
\hline., 0 &., 0 & 71,0 & $r$ & $\mid r \varepsilon, 0$. & $r, r$ & ru \\
\hline., 9 &., 9 & $\pi r, \varepsilon$ & $\varepsilon$ & $1 \pi \varepsilon, \Lambda$. & $r, r T$ & ra \\
\hline $0, r$ & $0, r$ & $7 \gamma, 7$ & rr & $1 r \varepsilon, 90$ & T, r r & F. \\
\hline., 0 &., 0 & 71,1 & $r$ & $1 r_{0}, 1$. & $r, r \varepsilon$ & -1 \\
\hline., 9 &., 9 & 79, & $\varepsilon$ & $1 T_{0, Y O}$ & r, ro & rr \\
\hline$r, \Lambda$ & $r, \Lambda$ & $\checkmark 1, \lambda$ & Ir & Iro, $\varepsilon$. & $r, r 7$ & $r$ \\
\hline., 0 &., 0 & $V T, r$ & $r$ & $1 r 0,00$ & $r, r v$ & $4 \varepsilon$ \\
\hline., 0 &., 0 & $V T, \lambda$ & $r$ & Iro,VV & $r, r \Lambda$ & ro \\
\hline., 9 &., 9 & $V r, V$ & $\varepsilon$ & $1 \% 0,10$ & $r, \pi 9$ & 4 \\
\hline 7,7 & 7,7 & $\Lambda ., r$ & $r \Lambda$ & $1 \% 7, .$. & $r, \varepsilon$ & v \\
\hline., 9 &., 9 & $\Lambda 1, r$ & $\varepsilon \varepsilon$ & $1+7, \leqslant 0$ & $r, \varepsilon r$ & $\mu$ \\
\hline 1,9 & 1,9 & $\Delta r, 1$ & $\Lambda$ & $1 \pi v, .0$ & $r, \varepsilon V$ & 49 \\
\hline., 0 &., 0 & $\Lambda r, r$ & $r$ & IrV,r. & $r, \varepsilon \wedge$ & $\leqslant$. \\
\hline., 0 &., 0 & $\wedge \varepsilon$, & $r$ & IrV, ro & $r, \varepsilon q$ & $\leqslant 1$ \\
\hline$r, \Lambda$ & $r, \Lambda$ & $\wedge \mathrm{V}, \Lambda$ & 17 & $1 r v, 90$ & r,or & $k r$ \\
\hline $1, \varepsilon$ & $1, \varepsilon$ & $19, r$ & 7 & $1{ }_{1} \Lambda, 1$. & $r, 0 \leqslant$ & Er \\
\hline$r, r$ & $r, r$ & 91,0 & 1. & $1 r q, .$. & r,, & $\leqslant \varepsilon$ \\
\hline., 9 &., 9 & 94,0 & $\varepsilon$ & $1+9,9$ & $r, 77$ & $\leqslant 0$ \\
\hline r...r & r...r & 90,1 & $1 \varepsilon$ & $1 \varepsilon ., 0$ & $r, 7 V$ & $\leq 7$ \\
\hline., 0 &., 0 & $97, Y$ & $r$ & $1 \varepsilon \cdot \lambda$. & $r, V r$ & $\varepsilon v$ \\
\hline., 9 &., 9 & $9 V, r$ & $\varepsilon$ & $1 \varepsilon ., 90$ & $r, v r$ & $\leqslant 1$ \\
\hline., 0 &., 0 & $9 \vee, V$ & $r$ & $\mid \varepsilon 1, v$. & $r, v \wedge$ & $\leqslant 9$ \\
\hline., 0 &., 0 & 91,1 & $r$ & $1 \leqslant r, r_{0}$ & $r, \wedge 9$ & 0. \\
\hline $1, \varepsilon$ & $1, \varepsilon$ & 99,0 & 7 & $1 \leqslant r, 90$ & $r, q r$ & 01 \\
\hline., 0 &., 0 & $1 \ldots$, & $r$ & $1 \leqslant 7,90$ & $r, i r$ & or \\
\hline $1 \ldots$, & $1 \ldots$, & & $\varepsilon r 7$ & \multicolumn{3}{|c|}{ المجموع } \\
\hline
\end{tabular}

جدول (9): التوزيع التكراري للدرجات المعيارية ونسب الذكاء الانحر افية لاختبار"ناجليري"

\begin{tabular}{|c|c|c|c|c|c|c|}
\hline المئين & المئين المصحح & تكرار متجمع صاعد & التكرارات & نسبة الذكاء الإنحرافية & الدرجة المعيارية & الرقم \\
\hline., 0 &., 0 & .5 & $r$ & $q \vee, \ldots$ & ., Y.- & .1 \\
\hline$r, r$ & $r, r$ & 2.8 & 1. & $1 \ldots, \ldots$ & $\ldots$ &.$r$ \\
\hline., 0 &., 0 & 3.3 & $r$ & $1.1, \ldots$ &.,.$V$ &.$r$ \\
\hline $1, \varepsilon$ & $1, \varepsilon$ & 4.7 & 7 & $1 . r, \ldots$ &., 14 & $\varepsilon$ \\
\hline., 0 &., 0 & 5.2 & $r$ & $1 . r, \ldots$ &.,$Y$. & .0 \\
\hline$r, r$ & $r, r$ & 7.5 & 1. & $1 . \varepsilon, \ldots$ &.,$T V$ & .7 \\
\hline 1,9 & 1,9 & 9.4 & $\Lambda$ & $1.0, \ldots$ & . &.$v$ \\
\hline., 9 &., 9 & 10.3 & $\varepsilon$ & $1.7, \ldots$ & ـ. & .1 \\
\hline
\end{tabular}




\begin{tabular}{|c|c|c|c|c|c|c|}
\hline., 0 &., 0 & $1 ., 1$ & $r$ & $1 \cdot v, \ldots$ & .,$\varepsilon V$ & .9 \\
\hline., 9 &., 9 & $11, . V$ & $\varepsilon$ & $1 \cdot \wedge, \ldots$ & . or & 1. \\
\hline$\Gamma, \wedge$ & $r, \Lambda$ & 10,0 & 17 & $1.9, \ldots$ &., 7 & .11 \\
\hline $1, \varepsilon$ & $1, \varepsilon$ & $1 \wedge, r$ & 7 & $111, \ldots$ &.,$V r$ & $.1 \%$ \\
\hline $1, \varepsilon$ & $1, \varepsilon$ & 19,8 & 7 & $\| r, \ldots$ & $\cdot, \wedge$ & $.1 \varepsilon$ \\
\hline $1, \varepsilon$ & $1, \varepsilon$ & $r 1,1$ & 7 & $11 r, .$. &.,$\wedge \mathrm{V}$ & .10 \\
\hline$r, r$ & $r, r$ & $r r, O$ & 1. & $\| 1 \varepsilon, \ldots$ &., 94 & .17 \\
\hline 1,9 & 1,9 & ro,V & $\wedge$ & $110, \ldots$ & $1, \ldots$ & $.1 \mathrm{~V}$ \\
\hline$r, r$ & $r, r$ & $r \Lambda, T$ & $1 \varepsilon$ & $117, \ldots$ & $1, . V$ & .11 \\
\hline$\varepsilon, r$ & $\varepsilon, Y$ & $r r, q$ & 11 & $11 \mathrm{~V}, \ldots$ & $1,1 \pi$ & .19 \\
\hline., 0 &., 0 & (r, & $r$ & $111, \ldots$ & $1, r$. &.$r$. \\
\hline$\varepsilon, r$ & $\varepsilon, Y$ & $r V, T$ & 11 & $119, \ldots$ & $1, Y V$ &.$M$ \\
\hline T,A & $r, \Lambda$ & $\varepsilon r, r$ & IT & $|r|, \ldots$ & $1, \varepsilon$ & Tr. \\
\hline $1, \varepsilon$ & $1, \varepsilon$ & $\varepsilon r, V$ & 7 & $I r r, \ldots$ & $1, \varepsilon V$ &.$T \varepsilon$ \\
\hline$r, r$ & $r, r$ & $\varepsilon 7,9$ & $1 \varepsilon$ & Irr,.. & $1,0 r$ & ro \\
\hline $1, \varepsilon$ & $1, \varepsilon$ & $\varepsilon \wedge, \varepsilon$ & 7 & $\mid r \varepsilon, \ldots$ & 1,7 & T \\
\hline$r, \Lambda$ & $r, \Lambda$ & $01, r$ & IT & Iro,... & $1,7 \mathrm{~V}$ &.$T V$ \\
\hline$r, \Lambda$ & $r, \Lambda$ & $0 \leqslant, 9$ & 17 & $|r|, \ldots$ & $1, V r$ & .ru \\
\hline 7,1 & 7,1 & $71,$. & $r 7$ & $I T V, \ldots$ & $1, \wedge$ & .19 \\
\hline 7,7 & 7,7 & $7 V, 7$ & $r \Lambda$ & $\mid r \Lambda, \ldots$ & $1, \wedge \mathrm{V}$ & $r$. \\
\hline $9, \varepsilon$ & $9, \varepsilon$ & $V V,$. & $\varepsilon$. & $1 r q, \ldots$ & 1,94 &. \\
\hline$\varepsilon, r$ & $\varepsilon, Y$ & $11, r$ & 11 & $1 \mu ., \ldots$ & $r, \ldots$ &.$r T$ \\
\hline ᄉ,. & ᄉ,. & $19, r$ & $r \varepsilon$ & $1 \pi 1, \ldots$ & $r, . V$ & rr \\
\hline 1,9 & 1,9 & $q V, r$ & $\Lambda$ & $\mid r \varepsilon, \ldots$ & $T, Y V$ & ד. \\
\hline 1,9 & 1,9 & 99,1 & $\Lambda$ & $1 r 0, \ldots$ & T,r &.$r v$ \\
\hline .9 &., 9 & $1 \ldots$, & $\varepsilon$ & $1 \mu 7, \ldots$ & T,E. & ri \\
\hline $1 \ldots$, & $1 \ldots$ & & $\varepsilon r\}$ & \multicolumn{3}{|c|}{ المجموع } \\
\hline
\end{tabular}

النتائج المتعلقة بالسؤال الثاني: نص هذا السؤال على أنه " هل يوجد فرق دال إحصائياً بين المتوسطات الحسابية لدرجات الطلاب والطالبات في

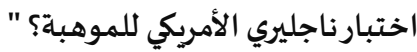
للإجابة عن السؤال فقد تم إيجاد المتوسط الحسابي والانحراف المعياري لدرجات الطابلاب المابل والطالبات على اختبار ناجليري الأمريكي للموهبة، ولاختبار

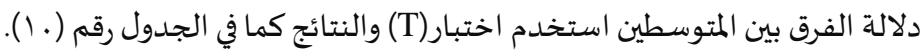

جدول ( ـ ): قيمة اختبار (T) للكشف عن دلالة الفروق بين درجات الطلاب والطالبات على اختبارناجليري للموهبة

\begin{tabular}{|c|c|c|c|c|c|c|}
\hline مستوى الدلالة & ق قيمةT & الانحراف المعياري & المتوسط الحسابي & درجات الحرية & العدد & البيان \\
\hline \multirow[t]{3}{*}{.,.$r$} & $r, \varepsilon$ & $1 ., r$ & $1 T ., 0$ & $r 11$ & $1 . r$ & طلاب \\
\hline & & , & TK, & & 111 & طالبات \\
\hline & & & & & rir & الاجمالي \\
\hline
\end{tabular}

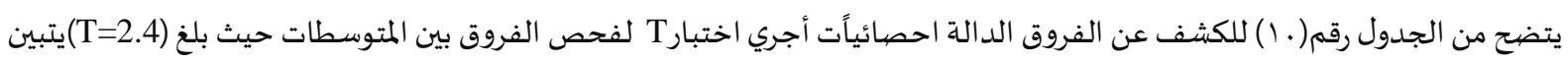

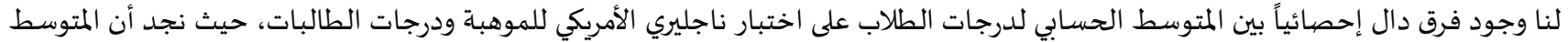

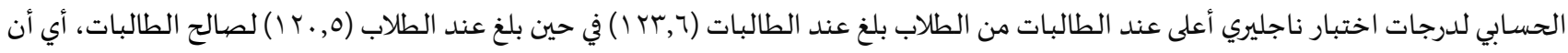
متوسط درجات الطالبات على اختبار ناجليري الأمريكي للموهبة أعلى من متوسط درجات الطلاب، وبفرق الطات دال إحصائياً. 
النتائج المتعلقة بالسؤال الثالث: نص هذا السؤال على أنه " هل يوجد فرق دال احصبائياً بين متوسط درجات الطلبة على اختبار ناجليري

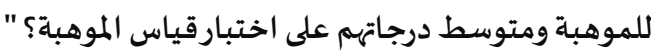

ولإجابة عن سؤال البحث فقد تم إيجاد المتوسط الحسابي والانحراف المعياري لمعاملات الذكاء الانحرافية لأفراد عينة البحث على كل من اختبار

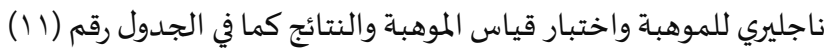

جدول(1) (1): قيم المتوسط الحسابي والانحراف المعياري لاختبار موهبة واختبارناجليري

\begin{tabular}{|c|c|c|c|c|c|}
\hline 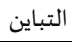 & متوسط الخطأ المعياري & الانحراف المعياري & المتوسط الحسابي & 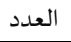 & 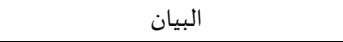 \\
\hline ro,7 &.,$T \leqslant r 97$ & 0,1 & ITr, & $\varepsilon r$ & نسبة الذكاء الانحرافية لاختبار موهبة \\
\hline $9 \uparrow, \varepsilon$ & . & $9, \mathrm{~V}$ & $|r|, V$ & $\varepsilon r q$ & نسبة الذكاء الانحرافية لاختبار ناجليري \\
\hline
\end{tabular}

من خلال الجدول رقم(1 (1) نجد ان متوسط نسبة الذكاء الانحرافية لعينة البحث في اختبار قياس الموهبة كان أعلى من متوسط نسبة

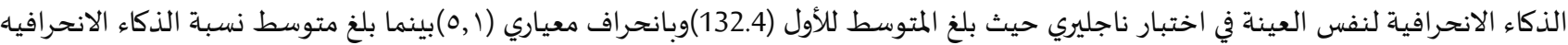

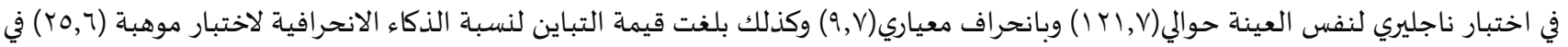
حين تباين نسبة الذكاء الانحرافية لاختبار ناجليري (ع,به) .كما تم فحص الفروق بين المتوسطات كلًا الاختبارين من خلال تطبيق اختبار T للعينات

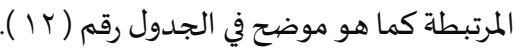

جدول ( r ): اختبار (T) للكشف عن دلالة الفروق بين درجات الطلاب على اختبارقياس الموهبة واختبارناجليري للموهبة

\begin{tabular}{|c|c|c|c|c|c|c|}
\hline مستوى الدلالة & درجة الحرية & قيمة T T & متوسط الخطأ المعياري & الانحراف المعياري & المتوسط & البيان \\
\hline${ }^{\prime}$, & ETO & $r \varepsilon, 7$ & ., £ & $\Lambda, \vee$ & $1 ., v$ & نسبة الذكاء الانحرافية لاختبار موهبة- نسبة الذكاء \\
\hline
\end{tabular}

من خلال الجدول رقم(r ا) نجد أن نتائج فحص دلالة الفروق تشير الى أنه يوجد فروق دالة احصائية بين متوسط درجات الطلاب في

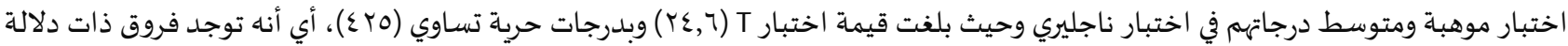
احصائية لصالح اختبار ناجليري للموهبة.

النتائج المتعلقة بالسؤال الر ابع: نص هذا السؤال على أنه " ما القدرة التنبؤية لاختبار ناجليري الأمريكي للموهبة بمقياس الموهبة المطبق في

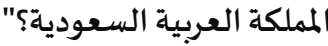

للإجابة عن هذا السؤال تم حساب معامل الانحدار ومعامل ارتباط بيرسون بين نسب الذكاء الانحرافية للطلاب في اختبار ناجليري وفي اختبار موهبة لعينة البحث الذكور والإناث. ويتضح من الجدول رقم (سا ) قيمة معامل بيرسون حيث أنه يدل على وجود علاقة ارتباطية بين الاختبارين بقيمة تساوي (7 ,.)، وهذه القيمة ذات دلالة احصائية عند مستوى دلالة 0 ., ..

جدول (r ا ): نتيجة فحص الارتباط بين نتائج قياس الموهبة واختبارناجليري للموهبة

\begin{tabular}{|c|c|c|c|}
\hline الانحراف المعياري & الخطأ المعياري & معامل التحديد & معامل ارتباط بيرسون \\
\hline$\varepsilon, 7$ &., 10 & .,17 & .,7 \\
\hline
\end{tabular}

وأيضاً للتحقق من قدرة اختبار ناجليري في التنبؤ بدرجة الطلاب في اختبار موهبة وذلك من خلال فحص الانحدار بطريقة ENTER وتطبيق تحليل التباين الاحادي تم التوصل الجدول رقم (ع () للكشف عن دلالة الفروق بين نسب الذكاء لاختبار قياس الموهبة واختبار ناجليري للموهبة.

جدول (ع (): اختبار (F) للكشف عن دلالة الفروق بين نسب الذكاء لاختبارقياس الموهبة واختبار ناجليري للموهبة

\begin{tabular}{|c|c|c|c|c|c|}
\hline مستوى الدلالة & قيمة F F & متوسط المربعات & درجات الحرية & مجموع المربعات & البيان \\
\hline$\cdot, .^{\mathrm{a}}$ & $\vee \wedge, q$ & 1791,9 & 1 & 1791,9 & مجموع مربعات الانحدار \\
\hline & & $r 1, \varepsilon$ & $\varepsilon r \varepsilon$ & $৭ \cdot \wedge r, \Lambda$ & مجموع مربعات البواقي \\
\hline & & & \&ro & $\cdot V V_{0}, \varepsilon$ & الاجمالي \\
\hline
\end{tabular}

بلغت قيمة (F=78.9)ومستوى الدلالة (. ., .) حيث يتبين لنا أنه يمكن التنبؤ بدرجات الطلاب في اختبار قياس الموهبة من خلال درجاتهم في اختبار ناجليري للموهبة وذلك في الجدول رقم (10). 
جدول(10): نتائج تحليل الانحدار

\begin{tabular}{|c|c|c|c|c|c|}
\hline \multirow[t]{2}{*}{ مستوى الدلالة } & \multirow[t]{2}{*}{ قيمة اختبار ت } & \multicolumn{2}{|c|}{ الأوزان غير المعيارية } & الأوزان غير المعيارية & \multirow[b]{2}{*}{ البيان } \\
\hline & & معامل بيتا & الخطأ المعياري & B & \\
\hline$\cdot, \cdot$ & $r V, \Lambda$ & & r,Arq & $1 . V, r_{0}$ & الثابت \\
\hline$\cdot, \ldots$ & 1,9 & •, & $\cdot, . r T$ & $\cdot, \mathrm{Y} \cdot \mathrm{V}$ & معامل نسبة الذكاء لاختبار ناجليري \\
\hline
\end{tabular}

يتضح من الجدول رقم (10 ) ومن خلال قيم معامل نسبة الذكاء لاختبار ناجليري للموهبة وقيمة الثابت أن معادلة التنبؤ تأخذ الصورة التالية: $Y=107.25+0.207 X$

حيث أن: (Y) هي درجة الطالب المعيارية في اختبار ناجليري.

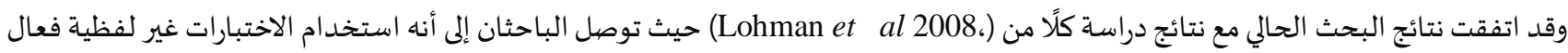
في تحديد الطلاب المتفوقين في الهندسة والرياضيات، كما سيحصل هؤلاء الطلاب أيضا على درجات عالية على الاختبارات اللفظية والكمية ودراسة (Dimitrov and Alharbi , 2015 ) التنبؤ بدرجات الطلاب في مقياس الإبداع من خلال مقياس موهباة.

التوصيات:

في ضوء النتائج التي توصل لها البحث الحالي، توصي الباحثة بما يلي:

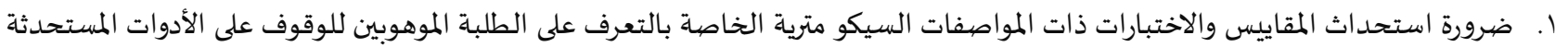

عالمياً. r. إضافة الاختبارات العالمية كمؤشرات لأداء الطلاب الموهوبين في المملكة العربية السعودية. r. استخدام اختبار ناجليري في عملية الكشف عن الطلبة الموهوبين، وذلك بعد تقنينه بصورة هائية على على البيئة السعودية.

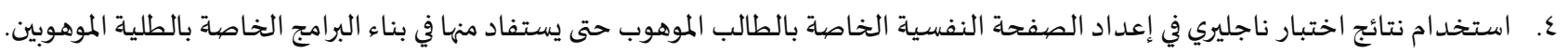

البحوث المقترحة:

في ضوء النتائج توصل البحث إلى ما يأتي:

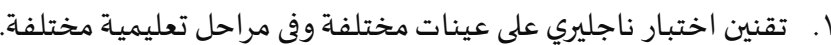
r. إجراء دراسة لبحث العلاقة بين نتائج اختبار ناجليري وغيره من الاختبارات الأخرى التي تعتبر نتائجها مؤشرات للموهبة.

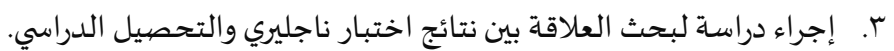
ع. إجراء المزيد من الدراسات حول موضوع الموهوبين وذوي الفئة المميزة باستخدام مقاييس أخرى وعينات أخرى وأهداف مختلفة في جامعات أخرى بالمملكة العربية السعودية ومقارنتها بالبحث الحاءلي.

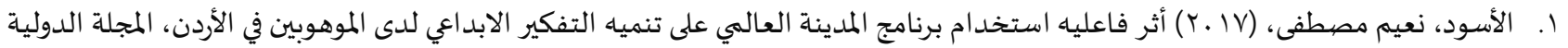

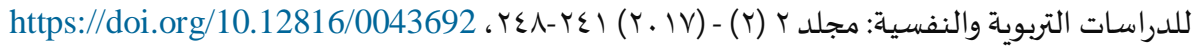

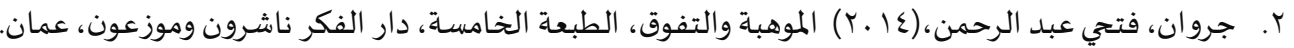

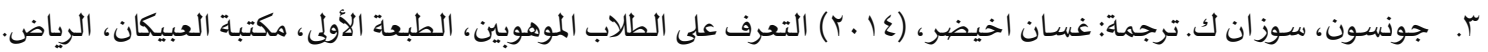

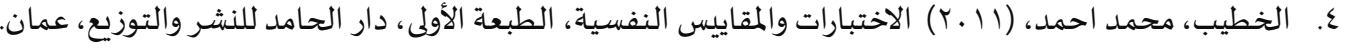

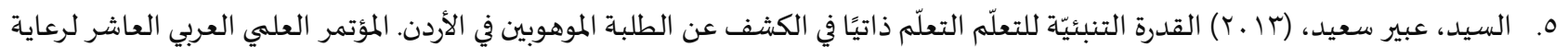

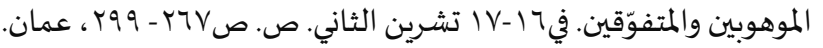




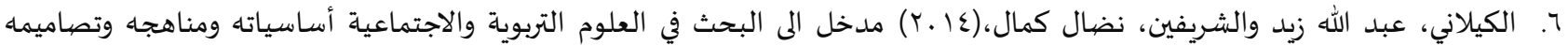

$$
\begin{aligned}
& \text { وأسـاليبا الإحصائية، الطبعة الرابعة، دار المسيرة للنشر والتوزيع. عمان. }
\end{aligned}
$$

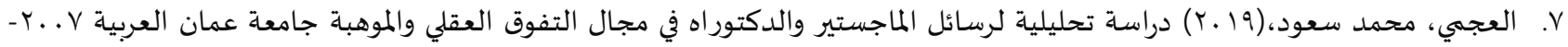

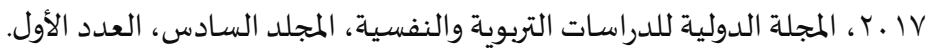

$$
\text { ثانياً: المراجع الأجنبية: }
$$

[1] Alharbi. K. \& Dimitrov. D, Relationships between multiple cognitive abilities and creativity of students across grade levels in Saudi Arabia. National Center Assessment in Higher Education. Technical Report \# 12 for Project \# 200800403, (2015)

[2] Brown. S. W., Renzulli. J. S., Gubbins. E. J., Siegle. D., Zhang. W., \& Chen. C. H., Assumptions underlying the identification of gifted and talented students, Gifted Child Quarterly, 49(1)(2005), 68-79, https://doi.org/10.1177/001698620504900107

[3] Feldhusin. John, Wood. Betty \& Dai. David, Gifted Students Perception of Their Talents, Gifted and Talented International, 12(1)(1997), 42-45

[4] Gambrell. J. \& Alharbi. K. ,The validity of creativity test. Part of the Mawhibah Student Selection Project for King Abdulaziz and his Companions Foundation for Giftedness and Creativity, National Center Assessment in Higher Education(2012) Report \#9

[5] Lohman. D. F., Korb. K. A., \& Lakin, J. M. , Identifying academically gifted English-language learners using nonverbal tests: A comparison of the Raven, NNAT, and CogAT. Gifted Child Quarterly, 52(4) 2008, 275-296, https://doi.org/10.1177/0016986208321808

[6] Naglieri. Jack, NNAT: Naglieri Nonverbal Ability Test, Individual Administration, Psychological Corporation. United States of America, (2003)

[7] Vista. A., \& Care. E., Gender differences in variance and means on the Naglieri Non-verbal Ability Test: Data from the Philippines, British Journal of Educational Psychology, 81(2)(2011),292-308, https://doi.org/10.1348/000709910x514004 


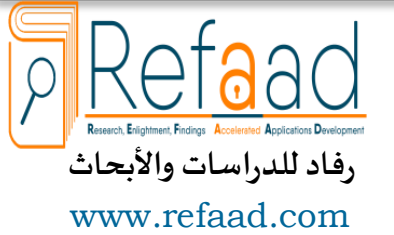

www.refaad.com
المجلة الدولية للدراسات التربوية والنفسية

e-ISSN 2520-4149, p-ISSN 2520-4130

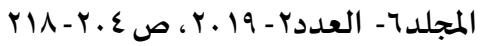

https://doi.org/DOI:10.31559/EPS2019.6.2.4
المجلة الدولية للدراسات

الثربوية والثفسية

Intensurtoun Jovenh of

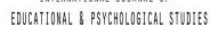

\title{
The Predictive Ability of Naglieri Test for Results of Mawhiba Talent Test Applied in Saudi Arabia
}

\author{
Shaher Khaled Suleiman \\ Professor at Department of Education and Psychology, University of Tabuk, KSA
}

\section{May Abdullah Al-Jasir}

Department of Education and Psychology, University of Tabuk, KSA

mayaljasir.k.s.a@gmail.com

\begin{abstract}
The research aimed at applying the American Naglieri Scale for detecting talented students in the Saudi environment and verifying the degree of a significant statistical correlation between it and the Saudi Talent Test "Mawhiba" which applied in Saudi Arabia as a criterion for acceptance in the gifted class es. The test was Applied on a pilot sample consisted of (52) students to examine both reliability and consistency. The research showed high values indicating the validity of the scale for application. The study sample consisted of (426) students from intermediate first grade. They were selected randomly in the following regions: Tabuk, Qassim, Makkah, Eastern and Asir. The results showed that there was a statistically significant difference between the arithmetical mean of male students' and female students' responses on the scale for the favor of females. There is statistical correlation between the Naglieri Test and Mawhiba Test (0.6). Where the Naglieri test is a good predictor for Mawhiba. The research presented many recommendations, which the most important is the use of the Naglieri test results in preparing the psychological page for talented students to be used in building talented students' programs and not to relay on collective tests in their classification and to use individual tests.
\end{abstract}

Keywords: Correlation; Global Tests; Talented.

\section{References:}

[1] Ạl'jmy. Mḥmd S'wd, Drạsh Tḥlylyh Lrsạyl Ạlmạjstyr Wạldktwrạh Fy Mjạl Ạltfwq Ạl'qly Wạlmwhbh Jạm‘̋̈ 'mạn Ạl'rbyh 2007-2017, A.lmjlh Ạldwlyh Lldrạsạt Ạltrbwyh Wạlnfsyh, A.lmjld Ạlsạds, A. Al'dd Ạlạ̉wl, (2019)

[2] Alạ̉swd. N'ym Mștfa, Ạtḥr Fạ 'lyh Ạstkhndạm Brnạmj Ạlmdynh Ạl ạ̣lmy 'la Tnmyh Ạltfkyr Ạlạbdạ y lda Ạlmwhwbyn Fy Ạlạ̉rdn, Ạlmjlh Ạldwlyh Lldrạsạt Ạltrbwyh Wạlnfsyh: Mjld 2(2)(2017), 241-248, https://doi.org/10.12816/0043692

[3] Brown. S. W., Renzulli. J. S., Gubbins. E. J., Siegle. D., Zhang. W., \& Chen. C. H., Assumptions underlying the identification of gifted and talented students, Gifted Child Quarterly, 49(1)(2005), 68-79, https://doi.org/10.1177/001698620504900107

[4] Feldhusin. John, Wood. Betty \& Dai. David, Gifted Students Perception of Their Talents, Gifted and Talented International, 12(1)(1997), 42-45 
[5] Gambrell. J. \& Alharbi. K. ,The validity of creativity test. Part of the Mawhibah Student Selection Project for King Abdulaziz and his Companions Foundation for Giftedness and Creativity, National Center Assessment in Higher Education(2012) Report \#9

[6] Alharbi. K. \& Dimitrov. D, Relationships between multiple cognitive abilities and creativity of students across grade levels in Saudi Arabia. National Center Assessment in Higher Education. Technical Report \# 12 for Project \# 200800403, (2015)

[7] Jrwạn. Ftḥy 'bd Ạlrḥmn, Ạlmwhbë Wạltfwq, Ạlțb đ̈ Ạlkhạmsẗ, Dạr Ạlfkr Nạsḥrwn Wmwz'wn, 'mạn, (2014)

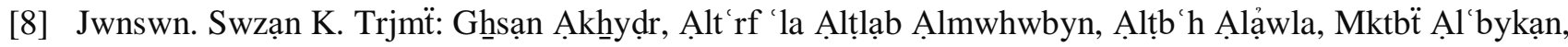
Ạlryạ̣, (2014)

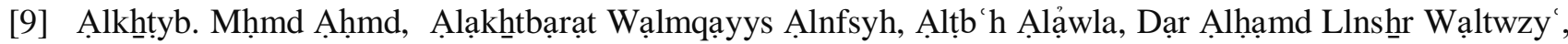
'mạn, (2011)

[10] Aalkylạny. 'bd Ạllh Zyd \& ạlsḥryfyn, Nḍạl Kmạl, Mdkḥl Ạly Ạlbḥth Fy Ạl'lwm Ạltrbwyh Wạlạjtmạ 'yh Ậsạsyạth Wmnạhjh Wtșạmymh Wạ̉sạlybh Ạlặhṣạyyh, Ạlțb`h Ạlrạb hh, Dạr Ạlmsyrh Llnsḥr Wạltwzy'. 'mạn, (2014)

[11] Lohman. D. F., Korb. K. A., \& Lakin, J. M. , Identifying academically gifted English-language learners using nonverbal tests: A comparison of the Raven, NNAT, and CogAT. Gifted Child Quarterly, 52(4) 2008, 275-296, https://doi.org/10.1177/0016986208321808

[12] Naglieri. Jack, NNAT: Naglieri Nonverbal Ability Test, Individual Administration, Psychological Corporation. United States of America, (2003)

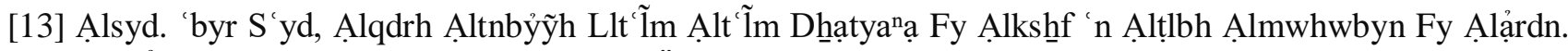

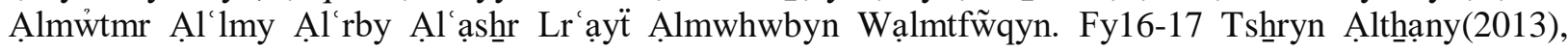
pp.267- 299, 'mạn.

[14] Vista. A., \& Care. E. , Gender differences in variance and means on the Naglieri Non-verbal Ability Test: Data from the Philippines, British Journal of Educational Psychology, 81(2)(2011),292-308, https://doi.org/10.1348/000709910x514004. 